\title{
Digital Sustainability in the Fourth Industrial Revolution
}

\author{
Vasja Roblek \\ Independent researcher, Slovenia \\ Maja Meško \\ University of Primorska, Faculty of management, Slovenia \\ Zlatka Meško Štok \\ University of Primorska, Faculty of management, Slovenia
}

\begin{abstract}
The fourth industrial revolution launched digitalization in manufacturing sector, business and human environment. This opens a question of influence to development of the digital sustainability concept and resource-efficiency in the focus on the design of smart cities and smart factories. Furthermore, it is also necessary to respect ethical rules when using private information. These factors are fundamental framework conditions for successful products. The aim of this paper is to present the known theory and practices of digital sustainability in the fourth industrial revolution and to investigate the changes that result from digital sustainability and influence on the corporate social digital responsibility development. In order to achieve this objective, a comprehensive review of journal articles, conference papers, books and edited volumes will be performed.
\end{abstract}

Keywords: Fourth industry revolution, digital sustainability, corporate social digital responsibility, smart city, smart products, innovation, ICT

JEL classification: 03, 033

\section{Introduction}

Web development can be classified as the one of the greatest innovations of the last twenty years. Since the beginning of nineties, the web has a significant impact and causes changes in both the economic and business as socio-political aspects (Bertoncelj et al., 2015).

Electronic commerce is introducing a whole new dimension of business. Internet technologies and e-commerce are joined by digital technology (Kaplan and Mikes, 2012).

Information and communication technology and digitalization of processes are leading to the development of digital sustainability that is important for the processes of digital heritage preservations (Mudogo, 2014).

With the development the German concept of Industry 4.0 in the last five years (2011-2016) occurred mainly in Europe to the proliferation of new economic policy based on high-tech strategies and represents a basic foundation for the development of concepts and technologies (Mosconi, 2015). That includes CyberPhysical Systems, the Internet of Things and the Internet of Services (Lassi et al., 2014; Ning and Liu, 2015). The characteristic of Industry 4.0 is increased competitiveness through smart equipment, making use of information about high-wage locations, demographic changes, resources and energetic efficiency and urban production (Heck and Rogers, 2014).

The goal of this paper is to find out the fundamental characteristics of digital 
sustainability through a holistic approach, in order to understand the influence of it to the development of the society and preservation of human heritage.

\section{Definition of sustainability}

First it has to be defined sustainability and specified the question what has to be sustained?

In 1987 the concept of sustainable development was defined for the first time by World Commission on Environment and Development at the United Nations. Sustainable development was defined as "a form of development or progress that meets the needs of the present without compromising future generations in meeting their needs" (World Commission on Environment and Development, 1987).

Sustainable development means increasing prosperity, in a responsible and balanced lifting of the material, social and environmental well-being of the present generation without compromising the existential conditions of future generations and the entire ecosystem. It means the transition from dependence to policies of sustainable policies (self) sufficiency (Bertoncelj et al., 2015). The economic, social and environmental aspects provide organizations and societies with competitive advantage that leads to viability and enables survival and growth (Yang, Lin, Chan and Sheu, 2010). The concept of sustainability includes also the cultural, political and religious aspects of the society (Jamrozy, 2007), which is important for the development of the inter-culture dialogue.

The economic aspects of sustainability, along with the social and environmental aspects, provide the rural area with the competitive advantage (e.g. development of the internet main roads) that leads to viability and enables the existence and further development (Dominici and Roblek, 2015).

In the past 25 years, culture has become an interdependent part on sustainability, and as such is extremely greatly contributing to sustainable development (Bertoncelj et al. 2014). Digitalization enables transfer of cultural heritage in virtual environments and so not only allows storage of invaluable recordings for the next generation, but also enables the access to heritage resources around the world from home in real time.

\section{ICT for sustainability}

ICT and sustainability are connected through several fields and their interdisciplinary approaches which are combining methods from computing and communications with methods from environmental and social sciences (Hilty and Aebischer, 2015). We are focused on cybernetics, human behavior and computers, digital sustainability and smartness sustainability.

\section{Cybernetics}

The organization is a complex consists of various subsystems. All these subsystems integrated into a whole working towards for common goal achieving. Management cybernetics is concerned with questions what things do and how they interact among one another. It covers in organization a field of knowledge, which can help organizations to gain further knowledge in situations where an organization cannot obtain any concrete knowledge (Potocan, Mulej and Kajzer, 2005).

The emergence of second cybernetic systems was influenced by the formation of interaction between the individual and its environment. The development of information technologies in the seventies led to the development of new channels of communication between the various systems that have tried to steer each other. 
The modern cybernetic science approach was bridging the micro-macro lap and has led to so integration of the individual with the society (Bailey, 1994). Science introduces the cybernetic theory on the epistemological assumption that the only relevant knowledge is obtained on observation of external reality (Easterby-Smith, Thorp and Lowe, 2002).

\section{Human behavior and computers}

It should be aware that the ability of developing and acquiring of the basic concepts of learning about using ICT and computer literacy, play an important role in the personal development and economic and social development of the society (Bisson, Stephenson and Vigurie, 2010).

The tools to study cognitive phenomena are using for a few years now. For this purpose, are using computer simulations, which explore the possibility of structuring human intelligence (Sun, 2008).Technology companies aimed at developing technologies that will allow computer visual recognition, speech recognition and identification of promising molecules for designing new drugs. Apple's virtual assistant Siri service already offers a technology called deep learning, which is based on a service called "Nuance Communications," and is intended for voice recognition (Markoff, 2012).

The Internet plays last 25 years in the field of computer science a very important role in the development of higher-order thinking in tertiary environments, based on dialogue and asynchronous text-based interaction that enables reflection and composition thoughtful answers.Dialogue and language use are fundamental to a higher form of knowledge, processes of articulation and exchange of ideas that lead to the very conceptualization of the contents. During innovation processes, it is necessary to create the conditions to ensure that online forums and other social tools support the development of higher level cognition. With this is in business and social environment able to make task so devised that encourage individuals to dealing with the problems and they are cognitively demanding (Fazel et al., 2015).

\section{Digital sustainability}

It is going for a question how to able the sustainable access to data? It is going for a process of enabling of access to content in the way that not only the data is retained, but also it can be rendered in future technical environments (Mudogo, 2014). This is important for the preservation of digital heritage, because according to the UNESCO guidelines for the preservation of digital heritage (2003), digital materials cannot be said to be preserved if access is lost.

\section{Smartness sustainability}

Industry 4.0 opens a new approach to the digital sustainability. Sustainability and resource-efficiency are increasingly in the focus of the design of smart cities and smart factories. Smart technologies are monitoring and archiving large amounts of data about human behavior. From the operators of "big data storage" is expected to respect ethical rules when using private information. These factors are fundamental framework conditions for successful products (Roblek, Meško and Krapež, 2016).

\section{Discussion and conclusion}

The content of the paper tries to give an answer how the ICT influence on sustainability? According to the literature review digital technologies are now used 
for creative expression in digital art digitization of cultural and natural heritage, science, technology and operations, and allowing the expression, communication, social interaction and education. Their expansion has led to the emergence of the digital economy. At the time of the digital economy, from 2008 onwards, the economic and social activities were globally integrated and they enable technology platforms such as the internet, mobile and sensory systems (Roblek, Meško, PejićBach and Bertoncelj, 2014).

\section{References}

1. Bailey, K. D. (2006), "Sociocybernetics and social entropy theory", Kybernetes, Vol 35 No 3/4, pp 375-384.

2. Bertoncelj, A. (2014), "Four-dimensional concept of sustainability and the development of an innovative economy", In Janeš, A. (Ed) "Co-creation of knowledge competence", Fakulteta za management, Koper, pp. 35-64.

3. Bertoncelj, A., Bervar, M., Meško, M., Naraločnik, A., Nastav, B., Roblek, V. and Trnavčevič, A. (2016), "Trajnostnirazvoj: ekonomski, družbeni in okoljskividiki" ("Sustaianble development: economic, social and environmental aspects"), Ljubljana, GV založba.

4. Dominici, G., Roblek, V. (2016), "Complexity Theory for a New Managerial Paradigm: A Research Framework", In RagužVrdoljak, I.,Podrug, N., Jelenc, L. (Eds.) Neostrategic Management, Springer, Cham, pp. 223-241.

5. Easterby-Smith, M., Thorp, R., Lowe, A. (2002), "Management research". London, Sage.

6. Fazel, H., Laplume, A. O., Muralidharan, E. (2015), "Technological Innovation and Adopter Self-Construal", International Journal of Innovation and Technology Management, Vol 12 No 4, pp. 1-23.

7. Heck, S., Rogers, M. (2014), "Are you ready for the resource revolution?", McKinsey Quarterly, No. 2, pp. 32-45.

8. Hilty, M.L., Aebischer, B. (2015), "ICT for sustainability: An emerging research field", In Hilty, M.L., Aebischer, B (Eds.), "ICT innovations for sustainability", Springer, Cham, pp. 3-36.

9. Jamrozy, U. (2007), "Marketing of tourism: a paradigms shift toward sustainability", International Journal of Culture, Tourism and Hospitality Research, Vol.1 No. 2, pp. 117-130.

10. Kaplan, M.A., Mikes, A. (2012), "Managing risks: a new framework", Harvard Business Review, Vol. 90 No. 6, pp. 49-60.

11. Lasi, H., Fettke, P., Kemper, H. G., Feld, T., Hoffmann, M. (2014), "Industry 4.0", Business \& Information Systems Engineering, Vol. 6 No 4, pp. 239 - 242.

12. Markoff, J. (2012), "Scientist sees promise in deep-learning programs", New York Times, available at:http://www.nytimes.com/2012/11/24/science/scientists-seeadvances-in-deep-learning-a-part-of-artificial-intelligence.html? $r=1$ \& $(5 / 15 / 2016)$

13. Mosconi, F. (2015), "The New European Industrial Policy: Global Competitiveness and the Manufacturing Renaissance". London, Routledge.

14. Mudogo M. S. (2014), "Status of digital heritage preservation management in Eastern Africa", The Electronic Library, Vol 32 No 3, pp. 363-374.

15. Ning, H., Liu, H. (2015), "Cyber-physical-social-thinking space based science and technology framework for the Internet of Things", Science China Information Sciences, Vol. 58 No. 3, pp. 1-19.

16. Potocan, V., Mulej, M., Kajzer, S. (2005), "Business cybernetics: a provocative suggestion", Kybernetes, Vol 34 No9-10, pp. 1496-1516.

17. Roblek, V., Meško, M., PejićBach, M., Bertoncelj, A. (2014), "Impact of knowledge management on sustainable development in the innovative economy", Dominici, G. (Ed.), Business Systems Laboratory-2nd International Symposium "Systems thinking for a sustainable economy". Advancements in Economic and Managerial Theory and Practice, UniversitasMercatorum, Rome, 1-13. 
18. Roblek, V., Meško, M., Krapež, A. (2016), "A complexity view of industry 4.0", Sage Open, Forthcoming.

19. Roblek, V., PejićBach, M., Meško, M., Bertoncelj, A. (2013), "The impact of social media to value added in knowledge-based industries", Kybernetes, Vol. 42 No.4, pp. 554-568.

20. Unescoguidelines for the preservation of digital heritage (2003), available at http://www.unesco.org/new/en/communication-and-

information/resources/publications-and-communication-materials/publications/fulllist/guidelines-for-the-preservation-of-digital-heritage/ (5/29/2016)

21. Yang, C. L., Lin, S. P., Chan, Y. H., Sheu, C. (2010), "Mediated effect of environmental management on manufacturing competitiveness: an empirical study", International Journal of Production Economics, Vol. 123 No 1, pp. 210-220.

22. World Commission on Environment and Development, (1987), "Report of the world commission on environment anddevelopment: Our common future", available at http://www.un-documents.net/ourcommon-future.pdf (5/24/2016)

\section{About the authors}

Vasja Roblek, M.Sc. is an independent researcher. He is cooperating on scientific research work within NGO Business Systems Laboratory. His current research areas are digital economy, knowledge management, organizational changes and sustainable development. The author can be contacted at vasja.roblek@gmail.com.

Maja Meško, Ph.D. holds a position of an Associate Professor of management at University of Primorska, Faculty of Management. Since 2013 she has been registered by European association for aviation psychology as a certificated human resource specialist. Her work, which includes around 200 bibliographical items, has been published in professional and academic journals. The author can be contacted at maja.mesko@fm-kp.si.

Zlatka Meško Štok, Ph.D. is an Associate Professor of management at University of Primorska, Faculty of Management. She has published several scientific articles in international and national journals and two books about knowledge management and marketing. The author can be contacted at stok.zlatka@gmail.com. 